\title{
STRATEGI PROMOSI KESEHATAN DALAM UPAYA PENURUNAN ANGKA KEMATIAN IBU (AKI) DI KOTA PEKALONGAN
}

\author{
Ardiana Priharwanti, Eka Fitriani, Nurul Baiti \\ Prodi Kesehatan Masyarakat, Fakultas Ilmu Kesehatan \\ Universitas Pekalongan
}

\begin{abstract}
Maternal mortality is one of the health problems in Indonesia. Maternal mortality cases in the city of Pekalongan in the range of 2012 - 2016 tends to increase. The annual report of the health program of the Health Office of Pekalongan City in 2016 shows that the number of deaths for the past five years is 37 cases, 5 cases in 2012, 6 cases in $2013-2015$ and 8 cases in 2016. While at the beginning of 2017 cases of maternal deaths in 2 cases. This study examines in depth the health promotion strategy in reducing MMR in Pekalongan City. The method used is qualitative study. Maternal mortality cases in Pekalongan City are caused by many factors including low level of mother's knowledge, health services and cultural factors. Promotion strategy to reduce AKI in Pekalongan City is through the strategy of $A B G$ (Advocacy, community building and community empowerment) through strengthening of cross-sector coordination both related government, building atmosphere with community leaders, cadres, and community. Strengthening the information network through technology to monitor the situation of pregnant women, mentoring by university institutions, Campus Guarding Generation Movement, and applying one of the pillars of Safe Motherhood that is Family Planning through the strengthening of family planning.
\end{abstract}

Keywords: AKI, decreasing effort, and strategy.

\begin{abstract}
ABSTRAK
Angka kematian ibu merupakan salah satu permasalahan kesehatan di Indonesia. Kasus kematian Ibu di Kota Pekalongan pada rentang tahun 2012 - 2016 cenderung meningkat. Laporan tahunan program kesehatan Ibu Dinas Kesehatan Kota Pekalongan tahun 2016 menunjukkan bahwa jumlah kematian Ibu lima tahun terakhir yaitu 37 kasus, 5 kasus pada 2012, 6 kasus berturut- turut pada 2013 - 2015 dan 8 kasus pada 2016. Sedangkan pada awal tahun 2017 sudah terdapat kasus kematian ibu sebanyak 2 kasus. Penelitian ini mengkaji secara mendalam strategi promosi kesehatan dalam upaya penurunan AKI di Kota Pekalongan. Metode yang digunakan adalah studi kualitatif. Kasus kematian ibu di Kota Pekalongan disebabkan oleh banyak faktor meliputi tingkat pengetahuan ibu yang kurang, layanan kesehatan dan faktor budaya. Strategi promkes untuk menurunkan AKI di Kota Pekalongan adalah melalui strategi ABG (Advokasi, bina suasana dan pemberdayaan masyarakat) melalui penguatan koordinasi lintas sektor baik pemerintah terkait, bina suasana dengan tokoh masyarakat, kader, dan masyarakat. Penguatan jaringan informasi melalui teknologi untuk memantau keadaan Ibu hamil, pendampingan oleh institusi perguruan tunggi yaitu Gerakan Kampus Mengawal Generasi., dan mengaplikasikan salah satu pilar dari Safe Motherhood yaitu Keluarga Berencana melalui penguatan kampung KB.
\end{abstract}

Kata Kunci : AKI, upaya penurunan, dan strategi. 


\section{PENDAHULUAN}

Angka kematian ibu merupakan salah satu permasalahan kesehatan di Indonesia. Hasil Survei Demografi dan Kesehatan Indonesia (SDKI) tahun 2012 menunjukan AKI di indonesia masih cukup tinggi, yaitu sebesar 359 per 100.000 kelahiran hidup. Data yang diperoleh dari Direktorat Bina Kesehatan Ibu dari daerah pada 2013, jumlah ibu yang meninggal karena kehamilan, persalinan, dan nifas pada 2013 sebanyak 5.019 kasus. Angka kematian ibu di Jawa Tengah cenderung meningkat dari tahun 2010 hingga 2014. Tahun 2010 jumlah ibu meninggal sebanyak 611, tahun 2011 sebanyak 668, tahun 2012 sebanyak 675, tahun 2013 sebanyak 668 dan tahun 2014 sebanyak 711. Kasus kematian ibu di Kota Pekalongan pada rentang tahun $2012-2016$ cenderung meningkat. Laporan Tahunan Program Kesehatan Ibu Dinas Kesehatan Kota Pekalongan Tahun 2016 menunjukan bahwa jumlah kasus kematian ibu lima tahun terakhir yaitu 37 kasus, 5 kasus pada 2012, 6 kasus berturut- turut pada 2013 - 2015 dan 8 kasus pada 2016. Sedangkan pada awal tahun 2017 sudah terdapat kasus kematian ibu sebanyak 2 kasus. Kematian ibu yang terjadi di Kota Pekalongan secara garis besar disebabkan oleh perdarahan dan eklamsia.Penyebab kematian ibu terbagi dalam tiga determinan, yaitu determinan dekat, antara dan jauh. Kementrian kesehatan dalam upaya penurunan AKI telah menetapkan Program intervensi melalui Penetapan Rencana Aksi Nasional (RAN) penurunan angka kematian ibu dengan tiga strategi yaitu peningkatan cakupan dan kualitas pelayanan kesehatan ibu, peningkatan peran pemerintah daerah dan swasta dalam upaya kesehatan ibu, dan pemberdayaan keluarga dan masyarakat. Berdasarkan pembahasan di atas, peneliti tertarik untuk mengkaji masalah Angka Kematian Ibu di Kota Pekalongan secara mendalam Strategi Promosi Kesehatan dalam Upaya Penurunan Angka Kematian Ibu (AKI) di Kota Pekalongan. Secara lebih khusus tujuan penelitian ini antara lain adalah:

a. Mengkaji secara mendalamadvokasi meliputi kebijakan, komitmen, dana, disposisi publik, dan sarana prasarana dalam upaya penurunan angka kematian ibu (AKI) di Kota Pekalongan.

b. Mengkaji secara mendalambina suasana meliputi koordinasi, sosialisasi program, dan pelatihan dalam upaya penurunan angka kematian ibu (AKI) di Kota Pekalongan.

c. Mengkaji secara mendalam pemberdayaan masyarakat meliputi kelas ibu dalam upaya penurunan angka kematian ibu (AKI) di Kota Pekalongan.

d. Menyusun strategi baru pada strategi promosi kesehatan dalam upaya penurunan angka kematian ibu (AKI) di Kota Pekalongan.

\section{METODE PENELITIAN}

Penelitian ini menggunakan metode deskriptif kualitatif. Sumber data dalam berupa data primer dan data sekunder. Data primer dalam penelitian ini diperoleh melalui wawancara mendalam. Data sekunder diperoleh melalui studi literatur dan dokumentasi. Metode pengumpulan data meliputi Wawancara Mendalam, Observasi dan Dokumentasi. Informan penelitian ini terdiri dari Informan Utama (pemegang program KIA Dinkes Kota Pekalongan) dan Informan Triangulasi (Bidan Koordinator Puskesmas Tirto dan Medono, Kader kesehatan Kelurahan, Ibu hamil peserta kelas Ibu). Metode analisis data melalui analisis kualitatif meliputi reduksi data, penyajian data, penarikan kesimpulan. Instrumen yang digunakan adalah pedoman wawancara dan catatan lapangan. Penelitian ini akan dilaksanakan pada bulan April sampai dengan Agustus 2017 di wilayah Kota Pekalongan. 


\section{LANDASAN TEORI}

\subsection{Gambaran Umum Kota Pekalongan}

Kota Pekalongan terletak didataran rendah pantai Utara Pulau Jawa, dengan ketinggian kurang lebih 1 meter di atas permukaan laut. Luas wilayah Kota Pekalongan 45,25 km² dengan jarak terjauh dari Utara ke Selatan $\pm 9 \mathrm{Km}$ dan dari Barat ke Timur $\pm 7 \mathrm{Km}$. Kepadatan penduduk di Kota Pekalongan cenderung meningkat seiring dengan kenaikan jumlah penduduk. Angka kepadatan penduduk di Kota Pekalongan Tahun 2016 adalah 6.631 jiwa per $\mathrm{Km}^{2}$. Rasio ketergantungan (Dependency Ratio) Kota Pekalongan tahun 2016 adalah sebesar 38 yang artinya bahwa setiap 100 penduduk usia produktif menanggung sekitar 38 orang penduduk usia tidak produktif.

\subsection{Situasi Derajat Kesehatan}

Derajat kesehatan masyarakat dipengaruhi oleh banyak faktor yang tidak hanya berasal dari sektor kesehatan dan non kesehatan. Adapun situasi derajat kesehatan di Kota Pekalongan adalah sebagai berikut:

1. Angka Kematian Neonatal (AKN)

Jumlah kematian neonatal di Kota Pekalongan pada tahun 2016 adalah sebanyak 38 kasus (6,52 per 1.000 kelahiran hidup) dengan angka kematian neonatal tertinggi terjadi di Puskesmas Kusuma Bangsa (7 kasus).

2. Angka Kematian Bayi (AKB)

Jumlah kematian bayi di Kota Pekalongan pada tahun 2016 adalah sebanyak 72 kasus (12,36 per 1.000 kelahiran hidup) dengan angka kematian bayi tertinggi terjadi di Puskesmas Kusuma Bangsa (12 kasus).

\subsection{Angka kematian balita (AKABA)}

Angka kematian balita di Kota Pekalongan tahun 2016 sebesar 17,69/1.000 kelahiran hidup (103 kasus), naik bila dibandingkan tahun 2015 yang hanya sebesar 12,50/1.000 kelahiran hidup.

\subsection{Angka Kematian Ibu (AKI)}

Jumlah kematian ibu di Kota Pekalongan pada tahun 2016 sebanyak 8 kasus $(137,36 / 100.000 \mathrm{KH})$. Jumlah kematian ibu ini mengalami peningkatan bila dibandingkan tahun 2015 yang hanya 6 kasus (101,33/100.000 KH). Apabila dibandingkan dengan target MDGs tahun 2015 sebesar 102/100.000 kelahiran hidup, maka AKI di Kota Pekalongan tidak mencapai target. Kasus kematian ibu di Kota Pekalongan selama kurun waktu 5 tahun terakhir dapat dilihat dalam grafik berikut :

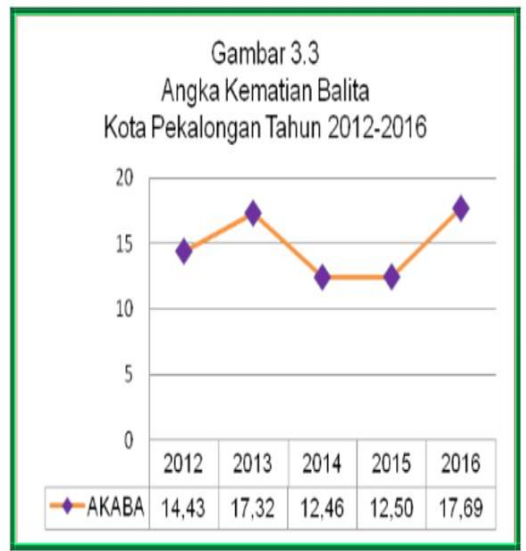

Adapun penyebab langsung kematian ibu maternal adalah eklampsia 3 kasus, perdarahan 3 kasus, emboli air ketuban 1 kasus, oedem pulmo 1 kasus dan semua kasus kematian ibu maternal terjadi di Rumah sakit. 


\section{HASIL DAN PEMBAHASAN}

\subsection{Persepsi Kondisi AKI}

Berdasarkan wawancara mendalam persepsi mengenai kondisi AKI di kota Pekalongan terdapat 6 kasus AKI. Pekalongan sangat layak dan penting untuk mendapat perhatian dari banyak pihak. Informan mengetahui bahwa harusnya angka kejadian adalah o (nol) kasus dan menurut informan angka kejadian di Kota Pekalongan cenderung naik dengan grafik yang tidak terlalu ekstrim. Melihat rerata pendidikan ibu di Kota Pekalongan sudah cukup baik, akan tetapi menurut informan rendahnya kesedaran dan tingkat pengetahuan ibu turut menjadi faktor penyebab kematian ibu.

\subsection{Tanggapan Program yang Telah Dilakukan}

Dalam menghadapi permasalahan pemerintah Kota Pekalongan telah banyak mencanangkan 29 program di antaranya adalah Peningkatan kualitas kunjungan neonates, peningkatan kapasitas petugas dalam penanganan, pembinaan kelas ibu, pendataan bumil dan balita kurang gizi. Masing-masing dari informan juga telah melakukan peran yang cukup di dalam program penurunan angka kematian ibu.

\subsection{Tanggapan Keterlibatan Pihak Lain}

Terdapat perbedaan tanggapan dari informan yang peneliti temui, sebagian dari mereka menjawab bahwa peran lintas sector masih dirasakan kurang bahkan merasakan bahwa tanggung jawab kesehatan masyarakat ada dipundak orang ataupun petugas kesehatan.

\subsection{Kendala yang Neonatus Esensial}

Secara normatif keterlibatan dan dukungan lintas sector sudah dirasakan cukup baik. Pada beberaoa kasus ditemukan kurangnya koordinasi antara petugas kesehatan dengan layanan pemerintahan.Kurangnya koordinasi tersebut lebih dikarenakan kurangnya kesadaran masyarakat tentang pentingnya kesehatan ibu dan anak.KIA (kesehatan ibu dan anak) masih belum menjadi skala prioritas bagi masyarakat, walaupun telah menjadi salah satu dari program kerja di dinas kesehatan setempat.

\subsection{Pembahasan}

Kesehatan ibu ditandai dengan indikator Angka Kematian Ibu (AKI). Selanjutnya kesehatan anak ditandai dengan indikator Angka Kematian Bayi (AKB). Angka kematian maternal dan angka kematian bayi merupakan ukuran bagi kemajuan kesehatan suatu negara, khususnya yang berkaitan dengan masalah kesehatan ibu dan anak. Angka kematian maternal merupakan indikator yang mencerminkan status kesehatan ibu, terutama risiko kematian bagi ibu pada waktu hamil dan melahirkan. Kejadian kematian ibu di Kota Pekalongan hingga trisemester I tahun 2017 ini mengalami 6 Kasus kematian ibu. Dari data tahun 2016 terdapat 8 kasus tahun 2015 terdapat 6 kasus Kematian ibu.

Menurut Linda (2004), masalah kematian maupun kesakitan pada ibu dan anak sesungguhnya tidak terlepas dari faktor-faktor sosial budaya dan lingkungan di dalam masyarakat dimana mereka berada. Rendahnya penggunaan fasilitas kesehatan seperti Puskesmas, rumah sakit dan 
sebagainya, seringkali kesalahan atau penyebabnya dilemparkan kepada faktor jarak antara fasilitas tersebut dengan masyarakat yang terlalu jauh ( baik jarak secara fisik maupun secara sosial) tarif yang tinggi, pelayanan yang tidak memuaskan dan sebagainya.

Kasus kematian ibu di Kota Pekalongan disebabkan oleh banyak faktor meliputi tingkat pengetahuan ibu yang kurang, layanan kesehatan dan faktor budaya. Masyarakat Kota Pekalongan masih banyak yang memiliki kecenderungan mempercayai mitos- mitos, termasuk mitos yang terkait dengan ibu hamil dan menyusui.Berdasarkan wawancara mendalam dengan salah seorang ibu hamil mereka masih mempercayai tradisi mutih pasca melahirkan.Mitos dan kepercayaan ini berkembang tidak terlepas dari peran dan pengaruh orangtua dan keluarga.

\subsection{Strategi Model Penurunan AKI di Kota Pekalongan}

Permasalahan kesehatan ibu dan anak serta kesehatan reproduksi masih menjadi fokus penting dalam bidang kesehatan. Salah satu upaya pengendalian AKI dapat dilakukan melalui promosi kesehatan. Promosi kesehatan melalui Strategi promkes untuk menurunkan AKI di Kota Pekalongan adalah peningkatan strategi ABG (Advokasi, Bina Suasana dan Gerakan Pemberdayaan). Advokasi disini adalah dengan memperkuat kebijakan penurunan AKI di kota Pekalongan melalui kelembagaan daerah.

Bina suasana melalui sosialisasi program kerja di lintas sektoral, membangun kemitraan dan jejaring yang kuat, dan menanamkan kesadaran yang tinggi pada setiap warga bahwa AKI adalah permasalahan bersama bukan masalah dari dinas kesehatan ataupun masalah perorangan. Koordinasi antara fasilitas kesehatan dengan masyarakat pun harus terbina dengan baik.Di era sekarang dimana sosmed (social media) bukan merupakan hal baru bagi masyarakat tentunya diharapkan dapat mendukung pada percepatan dan keberluasan informasi mengenai kasus AKI, pencegahan AKI dan kesehatan ibu pada umumnya.Kader, posyandu, pemangku adat, tokoh agama dan petugas kesehatan dapat berinteraksi dengan lebih dekat untuk mengawal ibu-ibu resti (resiko tinggi) agar mereka dapat melakukan persalinan yang aman dan sehat. Keterpaduan teknologi ini diupayakan dapat meningkatkan kecepatan tindakan rujukan. Gerakan pemberdayaan masyarakat memiliki kesadaran tinggi tentang pentingnya kesehatan ibu dan anak serta menciptakan kesadaran bahwa permasalahan AKI adalah permasalahan bersama bukan permasalahan dinas kesehatan maupun permasaahan perorangan.

Selain itu peran masyarakat tersebut juga perlu didukung oleh institusi pendidikan terutama mereka yang belajar dan terlibat dengan kesehatan ibu dan anak agar dapat memberikan kontribusi dalam menurunkan kematian ibu salah satunya melalui program pendampingan satu mahasiswa-satu bayi, yang pada tahun 2014 diresmikan oleh Ibu Menkes RI di salah satu Universitas menjadi Program 1000 hari awal kehidupan: Gerakan Kampus Mengawal Generasi. Program ini merupakan program pendampingan mahasiswa terhadap ibu hamil, 
hingga persalinan dan pemantauan bayinya (total selama 1000 hari). Ibu yang dikawal adalah ibu dari keluarga pra-sejahtera, dengan harapan ibu dan keluarga akan mendapatkan pendampingan dalam hal edukasi tentang kehamilan yang sehat, nutrisi, KB, imunisasi, ASI eksklusif dan Inisiasi Menyusui Dini (IMD) dan pertumbuhan-perkembangan bayi.

Pemerintah kota Pekalongan untuk menekan tingginya Angka Kematian Ibu, perlu mengaplikasikan salah satu pilar dari Safe Motherhood yaitu Keluarga Berencana. Dengan menggunakan kontrasepsi, seorang ibu dapat merencanakan keluarga lebih baik, karena tercegah dari jarak kehamilan yang terlalu dekat, tercegah dari kehamilan yang berisiko, tercegah dari kehamilan yang tak diinginkan, tercegah dari aborsi, dan dapat mengasuh anak-anak dan keluarganya dengan baik. Sehingga, upaya Keluarga Berencana merupakan investasi paling cost-effective dalam pembangunan. Secara global, upaya KB menjadi sangat krusial dalam pencapaian SDGs karena terbukti dapat menurunkan angka kemiskinan dan kelaparan, peningkatan pendidikan secara universal, kesetaraan gender, kesehatan ibu dan anak, pertumbuhan ekonomi, dan keberlangsungan lingkungan.

Pencetusan dan Penguatan kampung KB dirasakan perlu digiatkan kembali terutama di daerah-daerah perifer.Hal ini sejalan dan sesuai dengan salah satu nawacita pemerintahan Indonesia.Kajian tentang kampung KB tidak lepas dari dukungan lintas sekotoral, kerjasama dan kemitraan dengan lintas sektoral dan perguruan tinggi dapat dilakukan dalam penguatan kampung KB. Kampung KB tidak hanya memfokuskan pada peningkatan jumlah aseptor $\mathrm{Kb}$ akan tetapi juga penigkatan kualitas keluarga baik mengacu pada 8 pilar fungsi keluarga.

Selain strategi tersebut petugas kesehatan, baik dokter maupun bidan, perlu melakukan persiapan yang baik terhadap kemungkinan komplikasi yang dialami oleh ibu hamil karena persiapan yang baik akan memberi hasil yang baik pula. Direkomendasikan menggunakan semacam kotak emergensi preeklampsia untuk mempermudah manajemen alat dan bahan yang diperlukan selama keadaan emergensi. Kotak tersebut berisi semua kebutuhan alat dan bahan selama keadaan emergensi, disertai catatan isi kotak dan langkah-langkah pertolongan sebaiknya ditempatkan di tempat yang mudah dan sering dibaca. Kesigapan dan kesiapan hati yang baik (ikhlas) dalam menghadapi kasus-kasus risiko tinggi adalah modal utama petugas kesehatan, sebab dengan bekerja ikhlas, energi yang digunakan tidak akan melelahkan.

\section{PENUTUP}

Berdasarkan hasil penelitian yang dilakukan maka Strategi promosi kesehatan untuk menurunkan AKI di Kota Pekalongan adalah melalui strategi ABG (Advokasi Bina Suasana dan Gerakan Pemberdayaan).

1. Advokasi yaitu dengan memperkuat kebijakan penurunan AKI di kota Pekalongan melalui kelembagaan daerah.

2. Bina suasana melalui sosialisasi program kerja di lintas sektoral, membangun kemitraan dan jejaring yang kuat, dan menanamkan kesadaran yang tinggi pada 
setiap warga bahwa AKI adalah permasalahan bersama bukan masalah dari dinas kesehatan ataupun masalah perorangan. pengoptimalan penyebarluasan informasi melalui sosmed (social media) untuk mendukung percepatan dan keberluasan informasi mengenai $\mathrm{AKI}$, pemantauan, koordinasi antara kader, posyandu, pemangku adat, tokoh agama dan petugas kesehatan. Selain itu keterpaduan teknologi ini diupayakan dapat meningkatkan kecepatan tindakan rujukan.

3. Gerakan pemberdayaan melalui pengaplikasian salah satu pilar dari Safe Motherhood yaitu Keluarga Berencana. Pencetusan dan Penguatan kampung KB dirasakan perlu digiatkan kembali terutama di daerah-daerah perifer. Kemudian direkomendasikan menggunakan semacam kotak emergensi preeklampsia untuk mempermudah manajemen alat dan bahan yang diperlukan selama keadaan emergensi. Kotak tersebut berisi semua kebutuhan alat dan bahan selama keadaan emergensi, disertai catatan isi kotak dan langkah-langkah pertolongan sebaiknya ditempatkan di tempat yang mudah dan sering dibaca. Selain itu perlu keterlibatan institusi pendidikan melalui Gerakan Kampus Mengawal Generasi.

\section{UCAPAN TERIMA KASIH}

Ucapan terima kasih disampaikan kepada Bappeda Kota Pekalongan, Dinas Kesehatan, Puskesmas Tirto, Puskesmas Medono atas bantuan dan kerjasama dalam pelaksanaan penelitian ini.

\section{DAFTAR PUSTAKA}

Andrews, Gilly. 2010. Buku Ajar Kesehatan Reproduksi Wanita. EGC: Jakarta

Bangun, Sri Melda BR. 2014. Evaluasi pelaksanaan program EMAS untuk menurunkan AKI dan AKB di Puskesmas Batang Kuis dan RSU Sembiring Kab.Deli Serdang tanun 2013. Tesis FKM Universitas Sumatra Utara

Dinas Kesehatan Kota Pekalongan. 2016. Laporan Tahunan Program Kesehatan Ibu. Pekalongan

Dirjen Bina Pelayanan Medik Departemen Kesehatan. 2008. Pedoman Penyelenggaraan PONEK di Rumah Sakit. Jakarta

Iswarno, dkk. 2013. Analisis untuk Penerapan Kebijakan : Analisis Stakeholder dalam Kebijakan Program Kesehatan Ibu dan Anak di Kab. Kepahiang. Jurnal Kebijakan Kesehatan Indonesia Vol 02 Juni 2013

Kementerian Kesehatan RI. 2016. Buku Kesehatan Ibu dan Anak. Jakarta

Notoatmodjo, Soekedjo. 2005. Metodologi Penelitian Kesehatan. Rineka Cipta, Jakarta.

Notoatmodjo, Soekedjo. 2010. Promosi Kesehatan dan Ilmu Perilaku. Rineka Cipta, Jakarta.

Rahmi, Fifien Luthfia. 2016. Implementasi program EMAS sebagai upaya penurunan AKI dan AKB di Kab. Tegal. Jurnal Fisip Universitas Diponegoro

Sastroasmoro, Sudigdo. 2011. Dasar-dasar Metodologi Penelitian Klinis. Sagung Seto, Jakarta.

Stoppard, Miriam. 2009. Kehamilan dan Kelahiran. Erlangga: Jakarta

Sulaiman, Endang. 2012. Pemberdayaan Masyarakat di Bidang Kesehatan.UGM Press.Yogyakarta.

Tim Kajian AKI-AKA, Depkes RI.Kajian kematian ibu dan anak di Indonesia.

Badan Penelitian dan Pengembangan Kesehatan, Jakarta; Depkes R.I, 2004. 
UNFPA.Maternal mortality update 2002, a focus on emergency obstetric care.

New York, UNFPA; 2003.

World Health Organization. Maternal Mortality Available at: URL: www.who.int. Accessed October 19, 2017 